\title{
Cardiovascular risk management in rheumatoid and psoriatic arthritis: online survey results from a national cohort study
}

Premarani Sinnathurai ${ }^{1,2,3^{*}}$ (D), Alexandra Capon ${ }^{2}$, Rachelle Buchbinder ${ }^{4,5}$, Vibhasha Chand ${ }^{6}$, Lyndall Henderson ${ }^{3}$, Marissa Lassere ${ }^{7,8}$ and Lyn March ${ }^{1,2,3}$

\begin{abstract}
Background: Chronic inflammatory arthritis is associated with increased cardiovascular (CV) morbidity and mortality. Pharmacological management and healthy lifestyle modification is recommended to manage these risks, but it is not known how often these are utilised and whether there is any difference in their use between patients with different types of arthritis. The aim of this study was to determine and compare the proportion of participants with rheumatoid arthritis (RA) and psoriatic arthritis (PSA) receiving pharmacological or lifestyle management strategies for CV risk factors. The secondary objective was to identify factors associated with use of management strategies.

Methods: A survey was sent to online participants in the Australian Rheumatology Association Database, a voluntary national registry for inflammatory arthritis. Participants were asked whether they took medications for hypertension, hyperlipidaemia and diabetes, and to report their height, weight, level of physical activity, and dietary changes made. The use of management strategies was compared between participants with RA and PsA. Logistic regression analyses were performed to identify factors associated with physical activity and dietary changes.
\end{abstract}

Results: There were 858 respondents with RA and 161 with PsA (response rate 64.5\%). Pharmacological treatment was reported by $93 \%$ of participants with hypertension and $70 \%$ with hyperlipidaemia. All participants with diabetes reported being managed with dietary modification, pharmacological treatment, or a combination of both. Adequate physical activity was reported by $50.8 \%$. Only $27 \%$ of overweight or obese participants reported making any dietary change for their health in the past year. There was no difference between RA and PsA in reported utilisation of management strategies. Hyperlipidaemia and being overweight were associated with making dietary change. Obesity and arthritis disease activity were negatively associated with physical activity.

Conclusions: Most participants with RA and PsA reported using pharmacological treatment for CV risk factors. Relatively few reported using lifestyle modifications. Targeted lifestyle interventions should be implemented for RA and PsA patients.

Keywords: Rheumatoid arthritis, Psoriatic arthritis, Cardiovascular diseases, Medications, Diet, Physical activity

\section{Background}

Chronic inflammatory arthritis is associated with increased cardiovascular (CV) morbidity and mortality [1]. Systemic inflammation may cause insulin resistance and endothelial dysfunction, which then leads to atherosclerosis and vascular disease [2]. An increased risk of $\mathrm{CV}$

\footnotetext{
* Correspondence: Premarani.Sinnathurai@health.nsw.gov.au

${ }^{1}$ Institute of Bone and Joint Research, Kolling Institute, Northern Sydney

Local Health District, Sydney, NSW, Australia

${ }^{2}$ Department of Rheumatology, Royal North Shore Hospital, Reserve Road, St Leonards, NSW 2065, Australia

Full list of author information is available at the end of the article
}

mortality is well established in rheumatoid arthritis (RA). A meta-analysis of observational studies, published in 2008, demonstrated 50\% increased risk of CV death in patients with RA (meta-standardised mortality ratio (SMR) 1.50, 95\% confidence interval (CI) 1.39-1.61) compared with the general population [3]. Both traditional CV risk factors and markers of severity of RA are predictors of future $\mathrm{CV}$ events [4]. In recent years, there seems to have been a changing trend. In two cohorts in North America, mortality from CV disease in patients with incident RA since the year 2000 appears to be

(c) The Author(s). 2018 Open Access This article is distributed under the terms of the Creative Commons Attribution 4.0 International License (http://creativecommons.org/licenses/by/4.0/), which permits unrestricted use, distribution, and 
similar to that in general population controls $[5,6]$. It is not known whether this trend may be attributed to improved management of RA or more stringent screening and treatment for $\mathrm{CV}$ risk factors.

Psoriatic arthritis (PsA) is associated with an increased risk of the metabolic syndrome and other $\mathrm{CV}$ risk factors [7-10]. Previous analysis from the Australian Rheumatology Association Database (ARAD) showed that in this cohort, diabetes mellitus and high cholesterol were more common in participants with PsA than RA [11]. In the Consortium of Rheumatology Researchers of North America (CORRONA) Registry, PsA was associated with higher rates of obesity, diabetes mellitus and hypertriglyceridaemia, compared with RA [12]. Due to this high prevalence of traditional $\mathrm{CV}$ risk factors in PsA, it might be expected that CV mortality in PsA might be increased at a rate similar to, or even higher than in RA. However, the evidence relating to mortality in PsA is mixed with SMRs ranging from 0.82-1.62 [1315]. Several studies found an increase in all-cause mortality, with $\mathrm{CV}$ disease the most common cause of death $[16,17]$. One longitudinal cohort study demonstrated an overall increase in mortality, with a trend for improvement in survival over time [18]. However, other studies have found no increase in mortality compared with the general population $[19,20]$.

The reasons for this discrepancy in reported mortality in PsA, and for the apparent difference in mortality between PsA and RA are not yet known. There may be inherent differences in pathophysiology contributing to the difference observed between RA and PsA, although both are associated with chronic systemic inflammation. PsA is a heterogeneous disease and variable disease phenotype may contribute to the differences in mortality. Alternatively, variability in the management of $\mathrm{CV}$ risk factors may account for some of the diversity in mortality trends.

A EULAR task force produced recommendations for the management of $\mathrm{CV}$ risk in patients with inflammatory arthritis, which were updated in 2016 [21, 22]. The evidence available from their systematic literature review was far greater for RA than for PsA or ankylosing spondylitis. They advise CV risk assessment and management should be performed in accordance with national guidelines. They advise that healthy diet, regular exercise and smoking cessation should be recommended, based on accumulating evidence that physical inactivity is common in patients with RA and exercise may have beneficial effects on CV disease and systemic inflammation. The Group for Research and Assessment of Psoriasis and Psoriatic Arthritis (GRAPPA) recommend that all PsA patients should be encouraged to achieve and maintain a healthy body weight [23]. Similarly, recommendations from Spanish expert panels emphasise the importance of screening for $\mathrm{CV}$ disease and management in a multidisciplinary environment including promotion of regular exercise, healthy body weight and smoking cessation for patients with RA and PsA [24-26]. The Australian guidelines for the management of absolute CV disease risk also include a consensus-based recommendation that lifestyle advice and support be given to all adults, even those assessed to have low $\mathrm{CV}$ risk [27].

It is not known how often pharmacological management strategies and/or lifestyle modifications are currently being used by patients with inflammatory arthritis to manage $\mathrm{CV}$ risk, and whether there is any difference in the utilisation of these strategies in patients with RA or other inflammatory arthritides such as PsA. The primary objective of this study was to describe and compare the proportion of participants in ARAD with RA or PsA utilising pharmacological and/or lifestyle management strategies for $\mathrm{CV}$ risk factors. The secondary objective was to explore factors that are associated with reported utilisation of lifestyle modifications which can reduce $\mathrm{CV}$ risk.

\section{Methods}

ARAD is a voluntary national registry which collects longitudinal health information from people with inflammatory arthritis, including PsA, RA, ankylosing spondylitis and juvenile idiopathic arthritis, with diagnosis being confirmed by the treating rheumatologist [28]. The database was established in 2003 and has been previously described in detail [28]. Briefly, participants complete questionnaires every 6-12 months in online or paper format. These questionnaires include demographic data, past medical history, treatment for arthritis, adverse effects, infections and malignancies. Patient-reported pain is collected using pain visual analogue scale (VAS, $0=$ no pain to $100=$ pain as bad as it could be). Self-reported disease activity is also collected using global assessment VAS $(0=$ none to $100=$ extreme $)$. Written consent is obtained from all participants. Rigorous quality control and validation processes are undertaken to check and follow up any missing data to ensure database quality.

The Heart Health Survey was sent to all online ARAD participants with RA $(n=1295)$ and PsA $(n=285)$. This cross-sectional survey was sent in September 2015, with a reminder sent one month later to non-respondents. The survey was closed in December 2015. The survey asked participants about whether they took any medications for selected cardiovascular risk factors, and also about dietary changes and level of physical activity. Participants were asked:

- if they took any medications for hypertension, hyperlipidaemia and diabetes (yes or no); 
- whether they had made any dietary changes for their health in the last year, such as seeing a dietician or participating in a weight loss program (yes or no); if they had made a dietary change, participants were asked if they had attended a weight loss program run by a dietician or a commercial program, whether they had used meal replacements, had bariatric surgery, or attended an exercise program;

- how often they performed moderate physical activity, defined as physical activity associated with a moderate, noticeable increase in the depth and rate of breathing while still being able to whistle or talk comfortably. They were given options ranging from no physical activity to $30 \mathrm{~min}$ of moderate physical activity every day;

- if there were any medical conditions which limited their ability to participate in physical activity, including heart conditions, breathing difficulty, problems relating to a previous stroke, their arthritis, other conditions, or if there were no medical conditions limiting their activity;

- self-reported weight and height.

For all survey recipients, demographic information, arthritis medications, comorbidities and self-reported global assessment of disease activity (reported on a 0 to 100 VAS where a higher score indicates more disease activity) and pain (0 to 100 VAS where a higher score indicates more pain) were extracted from their most recent ARAD entry.

Statistical analysis was performed using IBM SPSS Statistics 22. Descriptive analyses were used to determine the proportion of participants with $\mathrm{CV}$ risk factors including smoking, hypertension, hyperlipidaemia, and diabetes. Self-reported height and weight were used to calculate body mass index (BMI) for respondents. Participants were classified as overweight if they had a BMI greater than or equal to $25 \mathrm{~kg} / \mathrm{m}^{2}$, and obese if their BMI was greater than or equal to $30 \mathrm{~kg} / \mathrm{m}^{2}$ [29]. Adequate physical activity was defined as performing $30 \mathrm{~min}$ of moderate intensity physical activity at least three days of the week. This definition was based on a consensus recommendation developed for people with arthritis [30], and is less stringent than the World Health Organisation guideline for adults which is a minimum of 150 min of moderate intensity physical activity per week [31]. For between group comparisons, Chi-squared and student $\mathrm{T}$-tests were used for categorical and continuous variables respectively. $P$ values of 0.05 or less were considered statistically significant.

Logistic regression was used to identify factors which were associated with physical activity and dietary changes. For these regression analyses, participants with RA and PsA were combined. However, only participants who had completed an ARAD questionnaire within 30 days of the Heart Health Survey, and therefore had recent measures of self-reported global assessment of disease activity and pain, were included in the regression analyses. Univariate analysis was first performed on potential predictors including age, gender, education level and employment status, diagnosis (RA or PsA), arthritis treatments (methotrexate, prednisone, biologic disease modifying anti-rheumatic drug (DMARD)), CV risk factors (hypertension, hyperlipidaemia, diabetes, smoking, obesity), disease duration, and disease activity as measured by patient global assessment and pain VAS. Low disease activity was defined as a patient global assessment score less than or equal to 20. Variables which were associated with the outcome of interest with $p \leq 0.25$ in the univariate logistic regression were entered into a multivariate logistic regression model and non-significant covariates removed via backwards stepwise elimination until only significant variables $(p<0.05)$ remained in the final model [32].

\section{Results}

Overall 1019 participants responded to the survey (overall response rate 64.5\%), including 858 with RA (response rate $66.3 \%$ ) and 161 with PsA (response rate 56.5\%) (Fig. 1). Table 1 summarises demographic information for responders and non-responders. Overall, responders were older, and had longer disease duration. Responders were more likely to be taking a biologic DMARD and methotrexate, but less likely to be smoking or working or studying full time.

Characteristics of responders, stratified by diagnosis, are shown in Table 2. RA responders were slightly older than PsA responders, and had slightly longer disease duration. There were more female respondents with RA, in keeping with the known epidemiology of this disease. Participants with PsA were more likely than those with RA to be overweight or obese $(131 / 161,81.4 \%$ vs $564 / 858$, $66.0 \%, p<0.001)$. Approximately half of all respondents $(518 / 1019,50.8 \%)$ were classified as physically active and the proportion of physically active respondents was similar in both disease groups. However, 189/1019 (18.5\%) reported that they had not performed any moderate intensity physical activity in the last week. The prevalence of other CV risk factors was similar between the two groups. Current cigarette smoking was reported by $6.1 \%$ of participants. Data regarding whether participants had received smoking cessation advice or management strategies were not collected in this study.

Pharmacological treatments, dietary changes and physical activity reported by participants are shown in Table 3 . Most participants with hypertension or hyperlipidaemia reported taking medications for these risk factors (93\% and $70 \%$ respectively). All participants who reported 


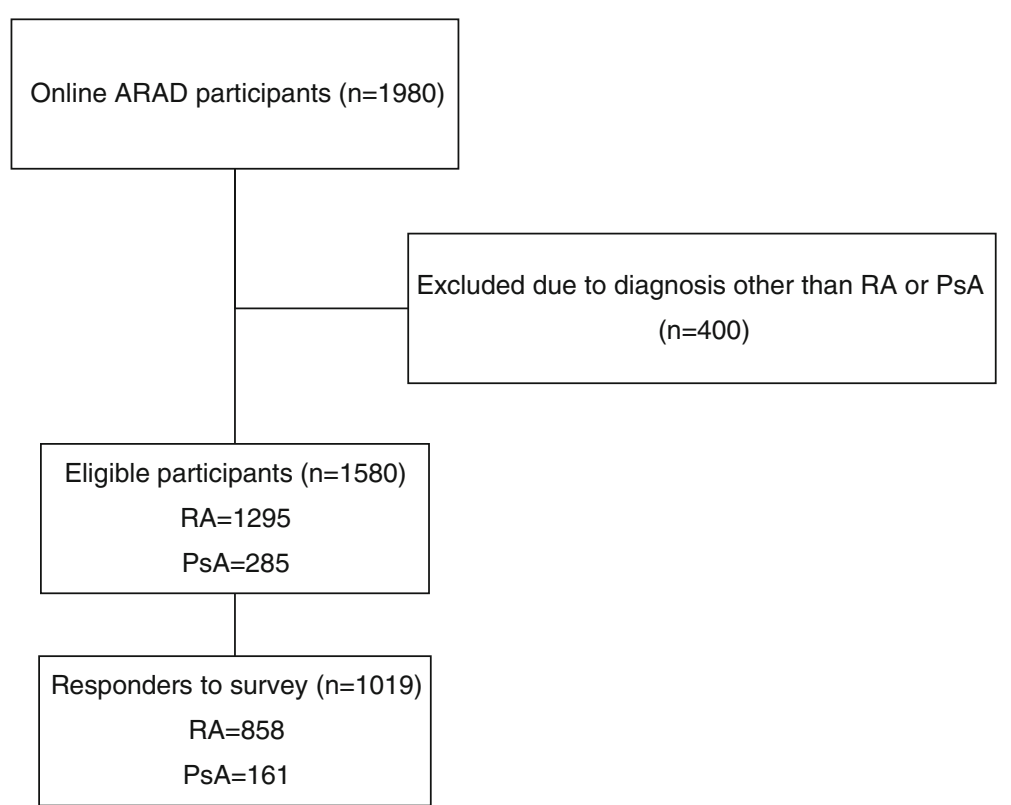

Fig. 1 Flow diagram of participant inclusion from ARAD. ARAD: Australian Rheumatology Association Database, RA: rheumatoid arthritis, PsA: psoriatic arthritis

having diabetes reported being managed with dietary modification, pharmacological treatment, or a combination of the two. Only about a quarter of RA and PsA participants who were overweight or obese reported that they had made any dietary change for their health in the past

Table 1 Characteristics of Responders and Non-Responders to Heart Health Survey

\begin{tabular}{llll}
\hline & $\begin{array}{l}\text { Responders } \\
(N=1019) \\
\text { Mean (SD) }\end{array}$ & $\begin{array}{l}\text { Non-Responders } \\
(N=561)\end{array}$ & $p$ \\
Mean (SD) & \\
\hline Age, years & $58(11)$ & $53(13)$ & $<0.001$ \\
Disease duration, years & $18(11)$ & $16(10)$ & 0.001 \\
& $N(\%)$ & $N(\%)$ & \\
Diagnosis & & & 0.002 \\
RA & $858(84.2)$ & $437(77.9)$ & \\
PsA & $161(15.8)$ & $124(22.1)$ & \\
Female & $752(73.8)$ & $407(72.5)$ & 0.6 \\
University/tertiary education & $605(59.4)$ & $313(55.8)$ & 0.17 \\
Full time work or study & $281(27.6)$ & $214(38.1)$ & $<0.001$ \\
Current biologic DMARD & $752(73.8)$ & $380(67.7)$ & 0.01 \\
Current methotrexate & $662(65.0)$ & $334(59.5)$ & 0.03 \\
Current prednis(ol)one & $311(30.5)$ & $188(33.5)$ & 0.22 \\
Current smoker & $62(6.1)$ & $49(8.7)$ & 0.05 \\
Hypertension & $332(32.6)$ & $160(28.5)$ & 0.10 \\
Diabetes & $87(8.5)$ & $42(7.5)$ & 0.5 \\
Hyperlipidaemia & $183(18.0)$ & $85(15.2)$ & 0.16 \\
\hline $\begin{array}{l}\text { SD standard deviation, } R A \text { rheumatoid arthritis, } \\
\text { disease modifying antirheumatic drug }\end{array}$ & & \\
\hline
\end{tabular}

year. For those who had made a change, use of meal replacements was the most commonly reported strategy, and 57/151 (37.8\%) RA and 11/36 (30.6\%) PsA reported participating in an exercise program.

In all participants, arthritis was by far the most commonly reported factor limiting physical activity (703/1019, $69.0 \%)$. In those who were classified as performing

Table 2 Demographics and cardiovascular risk factors for RA and PsA Responders

\begin{tabular}{llll}
\hline & RA (N=858) & PSA (N=161) & $p$ \\
& Mean (SD) & Mean (SD) & \\
\hline Age, years & $58(12)$ & $55(10)$ & $<0.001$ \\
Disease duration, years & $18(11)$ & $15(9)$ & 0.005 \\
& N (\%) & N (\%) & \\
Female & $657(76.6)$ & $95(59.0)$ & $<0.001$ \\
University/tertiary education & $504(58.7)$ & $101(62.7)$ & 0.3 \\
Full time work or study & $214(24.9)$ & $67(41.6)$ & $<0.001$ \\
Current biologic DMARD & $627(73.1)$ & $125(77.6)$ & 0.23 \\
Current methotrexate & $576(67.1)$ & $86(53.4)$ & 0.001 \\
Current prednis(ol)one & $295(34.4)$ & $16(9.9)$ & $<0.001$ \\
Current smoker & $52(6.1)$ & $10(6.2)$ & 0.9 \\
Hypertension & $279(32.5)$ & $53(32.9)$ & 0.9 \\
Diabetes & $73(8.5)$ & $14(8.7)$ & 0.9 \\
Hyperlipidaemia & $157(18.3)$ & $26(16.1)$ & 0.5 \\
Overweight or obese & $564(66.0)$ & $131(81.4)$ & $<0.001$ \\
Physically active & $418(48.7)$ & $83(51.6)$ & 0.5 \\
\hline
\end{tabular}

$R A$ rheumatoid arthritis, PSA psoriatic arthritis, SD standard deviation, DMARD disease modifying antirheumatic drug 
Table 3 Reported treatment for cardiovascular risk factors

\begin{tabular}{|c|c|c|c|c|}
\hline \multirow[t]{3}{*}{ CV risk factor } & \multirow[t]{3}{*}{ Treatment } & \multicolumn{2}{|c|}{ Responders with reported risk factor reporting receiving treatment } & \multirow[t]{3}{*}{$p$} \\
\hline & & RA & PSA & \\
\hline & & N (\%) & N (\%) & \\
\hline Hypertension & Pharmacological & 259/279 (92.8) & $50 / 53(94.3)$ & 0.7 \\
\hline Diabetes & Diet and/or pharmacological & $73 / 73(100.0)$ & $14 / 14(100.0)$ & N/A \\
\hline Hyperlipidaemia & Pharmacological & 109/157 (69.4) & $19 / 26(73.1)$ & 0.7 \\
\hline \multirow[t]{6}{*}{ Overweight or obese } & Any dietary change in the last year & $151 / 564(26.8)$ & $36 / 131(27.5)$ & 0.9 \\
\hline & Commercial weight loss program & 21/564 (3.7) & $3 / 131(2.3)$ & 0.4 \\
\hline & Health professional weight loss program & $44 / 564(7.8)$ & 7/131 (5.3) & 0.3 \\
\hline & Meal replacements & 53/564 (9.4) & 10/131 (7.6) & 0.5 \\
\hline & Exercise program & $57 / 564(10.1)$ & 11/131 (8.4) & 0.6 \\
\hline & Bariatric surgery & $4 / 564(0.7)$ & $1 / 131(0.8)$ & 0.9 \\
\hline
\end{tabular}

Treatment for hypertension, diabetes, hyperlipidaemia and being overweight or obese in RA and PsA respondents to the Heart Survey and a comparison of the two disease groups

$C V$ cardiovascular, $R A$ rheumatoid arthritis, PsA psoriatic arthritis, N/A not applicable

insufficient physical activity, 361/501 (72.1\%) reported that their arthritis limited their ability to participate in physical activity. Only $26(2.6 \%)$ reported heart conditions limited their activity, 14 (1.4\%) reported stroke as a limiting factor and 95 (9.3\%) reported breathing difficulties. Out of all respondents, $255(25.0 \%)$ reported there were no medical conditions limiting their physical activity, including 100/ $501(20.0 \%)$ who had insufficient physical activity. There were no significant differences in the utilisation of pharmacological or lifestyle management strategies between the RA and PsA groups.

The results for univariate and multivariate logistic regression on physical activity are shown in Table 4. There were 275 participants who had completed an ARAD questionnaire within 30 days of the Heart Health Survey and could therefore be included in the logistic regression. There were no significant demographic differences between the participants included in the logistic regression and those who were excluded (data not shown). In univariate analysis, lower self-reported disease activity was associated with higher odds of being physically active. Hypertension and being overweight or obese were associated with lower odds of physical activity. Self-reported pain and global assessment of disease activity were closely correlated (Pearson Correlation coefficient $=0.86)$ and therefore these variables were entered into separate multivariate regression models. However, in the multivariate analysis, pain was not significantly associated with physical activity, and therefore the results of the final model including self-reported global assessment of disease activity are presented in Table 4 . In the final model, there was a statistically significant inverse association between being physically active and being overweight or obese, while low self-reported disease activity was significantly positively associated with being physically active.
Results of the logistic regression on dietary change are shown in Table 5. In univariate analysis, reporting high cholesterol or being overweight or obese were associated with a higher odds of having made a dietary change for health reasons in the last year. However, current biologic DMARD treatment and self-reported low disease activity were associated with lower odds of having made a dietary change. In multivariate analysis, the associations with biologic DMARD treatment, high cholesterol and being overweight or obese persisted, but the association with self-reported low disease activity and low pain were no longer statistically significant.

\section{Discussion}

$\mathrm{CV}$ risk factors were common in this cohort with RA and PsA, in keeping with other reported RA and PsA cohorts $[10,33]$. Most of the participants with hypertension, hyperlipidaemia and diabetes reported receipt of pharmacological treatment, and there was no difference in utilisation rates between RA and PsA. Few studies have examined the management of $\mathrm{CV}$ risk factors in inflammatory arthritis. Using data from The Health Improvement Network medical record database in the United Kingdom [34], Jafri et al. reported similarly high utilisation of pharmacotherapy; approximately $85 \%$ of patients with hypertension, $65 \%$ with hyperlipidaemia and $45 \%$ with diabetes received prescriptions for pharmacotherapy. There was no difference in the frequency of prescription of therapy when comparing the PsA, RA and general population control cohorts in that study, and use of lifestyle modification was not examined as this was not readily identifiable in the coded database. In this study from ARAD, the use of lifestyle modifications known to improve CV risk was assessed by participant self-report. Only about half of the respondents reported adequate levels of physical activity, and less than one third of patients who were overweight 
Table 4 Odds and adjusted odds ratios for demographic and clinical characteristics associated with being physically active

\begin{tabular}{|c|c|c|c|c|c|c|}
\hline \multirow{2}{*}{$\begin{array}{l}\text { Univariate analysis } \\
\text { Variable }\end{array}$} & \multirow[b]{2}{*}{ OR $(95 \% \mathrm{Cl})$} & \multirow[b]{2}{*}{ p } & \multicolumn{2}{|c|}{ Multivariate analysis (baseline model)* } & \multicolumn{2}{|c|}{ Multivariate analysis (final model)* } \\
\hline & & & Adjusted OR (95\% Cl) & p & Adjusted OR (95\% Cl) & p \\
\hline Sex (female vs male) & $1.09(0.70-2.05)$ & 0.5 & - & - & - & - \\
\hline Diagnosis (PsA vs RA) & $0.80(0.42-1.52)$ & 0.5 & - & - & - & - \\
\hline Current biologic DMARD & $0.99(0.58-1.69)$ & 1.0 & - & - & - & - \\
\hline Current methotrexate & $1.31(0.81-2.12)$ & 0.3 & - & - & - & - \\
\hline Current prednis(ol)one & $0.90(0.54-1.48)$ & 0.7 & - & - & - & - \\
\hline Current hypertension & $0.58(0.35-0.98)$ & 0.04 & $0.65(0.38-1.11)$ & 0.11 & - & - \\
\hline Current hyperlipidaemia & $1.20(0.67-2.14)$ & 0.6 & - & - & - & - \\
\hline Current diabetes & $1.04(0.44-2.49)$ & 0.9 & - & - & - & - \\
\hline Current smoker & $1.22(0.40-3.73)$ & 0.7 & - & - & - & - \\
\hline Overweight or obese & $0.51(0.31-0.84)$ & 0.01 & $0.59(0.35-0.99)$ & 0.04 & $0.56(0.33-0.93)$ & 0.03 \\
\hline University/tertiary education & $1.20(0.74-1.93)$ & 0.5 & - & - & - & - \\
\hline Full time work or study & $0.98(0.57-1.66)$ & 0.9 & - & - & - & - \\
\hline Age $\geq 65$ years & $1.17(0.70-1.94)$ & 0.6 & - & - & - & - \\
\hline Disease duration $\geq 5$ years & $0.68(0.27-1.75)$ & 0.4 & - & - & - & - \\
\hline Low self-reported disease activity (VAS $\leq 20$ ) & $1.88(1.14-3.09)$ & 0.01 & $1.69(1.01-2.82)$ & 0.05 & $1.71(1.03-2.85)$ & 0.04 \\
\hline Low pain (VAS $\leq 20)$ & $1.57(0.95-2.61)$ & 0.08 & - & - & - & - \\
\hline
\end{tabular}

Combined analysis including RA and PsA respondents, $N=275$

$O R$ odds ratio, $C l$ confidence interval, RA rheumatoid arthritis, PSA psoriatic arthritis, DMARD disease modifying antirheumatic drug, VAS visual analogue scale *Variables with $p \leq 0.25$ in the univariate logistic regression were entered into the multivariate logistic regression baseline model and non-significant covariates removed via backwards stepwise elimination until only significant covariates remained in the final model. Stepwise backwards elimination process can be seen in Additional file 1 . Nagelkerke $\mathrm{R}^{2}$ for model $=0.06$

Table 5 Odds and adjusted odds ratios for demographic and clinical characteristics associated with making dietary change

\begin{tabular}{|c|c|c|c|c|c|c|}
\hline \multirow{2}{*}{$\begin{array}{l}\text { Univariate analysis } \\
\text { Variable }\end{array}$} & \multirow[b]{2}{*}{ OR $(95 \% \mathrm{Cl})$} & \multirow[b]{2}{*}{$p$} & \multicolumn{2}{|c|}{ Multivariate analysis (baseline model)* } & \multicolumn{2}{|l|}{$\begin{array}{l}\text { Multivariate } \\
\text { analysis (final model)* }\end{array}$} \\
\hline & & & Adjusted OR (95\% Cl) & $p$ & Adjusted OR (95\% Cl) & $p$ \\
\hline Sex (female vs male) & $1.72(0.81-3.62)$ & 0.16 & $1.90(0.86-4.20)$ & 0.11 & - & - \\
\hline Diagnosis (PsA vs RA) & $0.87(0.38-1.98)$ & 0.7 & - & - & - & - \\
\hline Current biologic DMARD & $0.44(0.23-0.82)$ & 0.01 & $0.42(0.21-0.82)$ & 0.01 & $0.36(0.19-0.71)$ & 0.003 \\
\hline Current methotrexate & $1.12(0.61-2.06)$ & 0.7 & - & - & - & - \\
\hline Current prednis(ol)one & $0.82(0.43-1.57)$ & 0.6 & - & - & - & - \\
\hline Current hypertension & $1.63(0.88-3.04)$ & 0.12 & $1.26(0.63-2.51)$ & 0.51 & - & - \\
\hline Current hyperlipidaemia & $2.08(1.07-4.06)$ & 0.03 & $2.06(0.99-4.31)$ & 0.05 & $2.20(1.09-4.44)$ & 0.03 \\
\hline Current diabetes & $1.60(0.60-4.31)$ & 0.4 & - & - & - & - \\
\hline Current smoker & $0.73(0.16-3.42)$ & 0.7 & - & - & - & - \\
\hline Overweight or obese & $3.91(1.76-8.67)$ & 0.001 & $4.08(1.76-9.47)$ & 0.001 & $4.49(1.97-10.26)$ & $<0.001$ \\
\hline University/tertiary education & $0.94(0.52-1.72)$ & 0.9 & - & - & - & - \\
\hline Full time work or study & $0.94(0.48-1.85)$ & 0.9 & - & - & - & - \\
\hline Age $\geq 65$ years & $1.10(0.59-2.08)$ & 0.8 & - & - & - & - \\
\hline Disease duration $\geq 5$ years & $1.33(0.37-4.73)$ & 0.7 & - & - & - & - \\
\hline Self-reported low disease activity (VAS $\leq 20$ ) & $0.43(0.22-0.87)$ & 0.02 & $0.55(0.26-1.16)$ & 0.12 & - & - \\
\hline Low pain (VAS $\leq 20$ ) & $0.46(0.22-0.94)$ & 0.03 & - & - & - & - \\
\hline
\end{tabular}

Combined analysis including RA and PsA respondents, $N=275$

$O R$ odds ratio, $C l$ confidence interval, RA rheumatoid arthritis, PSA psoriatic arthritis, DMARD disease modifying antirheumatic drug, VAS visual analogue scale *Variables with $p \leq 0.25$ in the univariate logistic regression were entered into the multivariate logistic regression baseline model and non-significant covariates removed via backwards stepwise elimination until only significant covariates remained in the final model. Stepwise backwards elimination process can be seen in Additional file 1. Nagelkerke $\mathrm{R}^{2}$ for model $=0.15$ 
or obese report having made a dietary change for their health in the last year.

Respondents reporting high cholesterol or obesity were more likely to have made a dietary change than those without these risk factors, and participation in a weight loss program run by a health professional was the most commonly reported method of dietary change. Use of biologic DMARDs was negatively associated with making a dietary change, but the reasons for this association are unclear. The analyses identifying factors associated with physical activity and dietary changes were exploratory, and it is possible that some significant findings may have occurred by chance.

On a global level, physical inactivity has been described as a pandemic which should be a public health priority [35]. However, arthritis has been recognised as a barrier to physical activity in patients with obesity, heart disease and diabetes [36-38]. This study from ARAD highlights the low level of physical activity in patients with inflammatory arthritis, despite the known health benefits [39, 40]. Approximately half of all respondents were classified as physically inactive, and obesity was associated with being physically inactive. Arthritis was the most commonly reported condition limiting physical activity and those with low self-reported disease activity were more likely to be physically active. However, other comorbidities and demographic factors including age and level of education were not significantly associated with physical activity. In a cross-sectional international study of patients with RA published in 2008, even higher rates of physical inactivity were reported than in this Australian cohort; only $13.8 \%$ of patients reported physical exercise three or more times weekly [41]. In the 2002 National Health Interview Survey in the United States, $63 \%$ of adults with arthritis did not meet the arthritis expert panel recommendation for physical activity, compared with $61 \%$ of those without arthritis [42]. Using data from the 2000 Behavioral Risk Factor Surveillance System survey in the general United States population, Hootman et al. reported $30.8 \%$ of people with arthritis are completely inactive, compared to $25.8 \%$ of those without arthritis [43].

There are some limitations to this study. Due to the self-reported nature of ARAD, clinical information such as blood pressure readings and blood lipid or glucose levels were not available. It is possible that some respondents in ARAD had undiagnosed $\mathrm{CV}$ risk factors which were not detected through self-report. Also, it was not possible to assess the severity of $\mathrm{CV}$ risk factors, or the adequacy of treatment. In a Dutch cross-sectional cohort study in which blood pressure and cholesterol levels were measured, $42 \%$ of patients with RA received inadequate lipid-lowering and/or antihypertensive treatment, based on Dutch CV risk management guidelines [44]. Online ARAD participants who did not respond to the survey were more likely to be working full time and less likely to be taking biologic DMARDs than survey responders. It is therefore possible that this non-responder group had less severe disease and may have different patterns of physical activity or $\mathrm{CV}$ risk management. The number of participants was relatively small, particularly in the PsA subgroup, and the number of participants who were included in the regression analysis, which may have affected the analysis. Furthermore, participants in ARAD are predominantly Caucasian, with English as their first language and over half of respondents had a university or other tertiary level education. Therefore, the findings from this study may not be generalisable to the wider population of people with RA and PsA.

The Heart Health survey focussed on medical conditions limiting physical activity but did not investigate social, environmental or psychological barriers to physical activity and dietary change. The $\mathrm{R}^{2}$ values for the regression models were low ( 0.06 for physical activity and 0.15 for dietary change) indicating that there are factors which are not accounted for which may be associated with lifestyle modifications. In other published studies, older age, lower education, self-efficacy and pain have been associated with physical activity status in people with arthritis [42, 45]. A qualitative study among adults with arthritis identified a multitude of physical, psychological, social and environmental barriers to exercise [46]. Pain and lack of exercise programs or facilities specifically for people with arthritis emerged in almost all groups. Patients with RA have reported that fear for safety, and uncertainty regarding what type and amount of activity is recommended is a barrier to participating in physical activity or exercise [47].

There is a need for further research to identify barriers that prevent patients from taking up dietary modification and regular physical activity, so that appropriate, targeted interventions can be designed to combat these problems. The population health strategies encouraging physical activity in the general population are not always appropriate for those with arthritis who face particular challenges relating to their disease. However, even light and very light intensity exercise is associated with favourable cardiovascular markers and lower disease activity in rheumatoid arthritis [48]. Although the current goal in treat to target strategies in RA [49] and PsA [50] is to maximise long-term health-related quality of life, including physical function and participation in work and social activities, the primary method to achieve this goal is focussed on the use of DMARDs to control inflammation. Multidisciplinary models of care are needed 
to address not only pharmacological treatment for inflammation, but also target achievable physical activity and healthy weight goals to improve patient outcomes, both disease-specific and relating to long-term $\mathrm{CV}$ risk.

\section{Conclusions}

In this study, most participants with RA and PsA were managing their $\mathrm{CV}$ risk factors using pharmacological treatments. However, relatively few had undertaken lifestyle modifications to improve their $\mathrm{CV}$ risk. There was no difference in the utilisation of these management strategies between those with RA and PsA. Treating clinicians should look beyond pharmacological management and address targeted lifestyle interventions for their RA and PsA patients.

\section{Additional file}

Additional file 1: Stepwise regression for multivariate logistic regression models. Stepwise backwards elimination of covariates to build final multivariate logistic regression models for physical activity and dietary change. (PDF 234 kb)

\section{Abbreviations}

ARAD: Australian Rheumatology Association Database; BMI: Body mass index Cl: Confidence interval; CORRONA: Consortium of Rheumatology Researchers of North America; CV: Cardiovascular; DMARD: Disease modifying antirheumatic drug; GRAPPA: Group for Research and Assessment of Psoriasis and Psoriatic Arthritis; OR: Odds ratio; PsA: Psoriatic arthritis; RA: Rheumatoid arthritis; SD: Standard deviation; SMR: Standardised mortality ratio; VAS: Visual analogue scale

\section{Acknowledgements}

We thank Australian rheumatologists and patients for contributing data to ARAD. We would also like to acknowledge the contributions of Joan McPhee, and the ARAD Steering Committee with special thanks to Graeme Carroll and Claire Barrett.

\section{Funding}

Premarani Sinnathurai is supported by a Commonwealth Government of Australia National Health \& Medical Research Council (NHMRC) postgraduate scholarship and received the SA LSS Support Group Grant \& Arthritis Australia \& State and Territory Affiliate Grant funded by Arthritis South Australia 2015. Rachelle Buchbinder is funded by an NHMRC Senior Principal Research Fellowship. ARAD is currently supported by unrestricted educational grants administered through the Australian Rheumatology Association from AbbVie Pty Ltd. Pfizer Australia, Sanofi Australia, Celgene Australian \& NZ, Bristol-Myers Squibb Australia Pty Ltd. Previous sponsorship for ARAD included an NHMRC Enabling Grant [384330], Amgen Australia Pty Ltd., Aventis, AstraZeneca, Roche, Monash University, Cabrini Health. Infrastructure support for ARAD received from Cabrini Health, Monash University, Royal North Shore Hospital and the Australian Rheumatology Association.

\section{Availability of data and materials}

The datasets analysed during the current study are not publicly available due to Human Research Ethics Committee requirements, but are available from the corresponding author on reasonable request.

\section{Authors' contributions}

All authors (PS, AC, RB, VC, LH, ML and LM) were substantially involved in study concept and design. PS, AC and LM analysed and interpreted the data. PS drafted the manuscript. All authors, critically reviewed the manuscript and approved the final version to be published.

\section{Ethics approval and consent to participate}

Twenty ethics committees and organisations have granted approval for ARAD across each state in Australia (New South Wales: Northern Sydney Local Health District, Cancer Council NSW; Victoria: Cabrini Health, Monash University, Royal Children's Hospital, St Vincent's Hospital, Cancer Council Victoria; Queensland: Queensland Government; South Australia: The South Australian Department of Health and Ageing, Women's and Children's Hospital SA Health Network; Western Australia: Department of Health WA, Fiona Stanley Hospital, Rockingham General Hospital, Royal Perth Hospital, Southern Metropolitan Health Service, Government of WA; Tasmania: Tasmania Health, University of Tasmania; the Australian Capital Territory: ACT Health and Community Care). Approval has also been granted by the Australian Institute of Health and Welfare, the Australian Government Department of Health and the Department of Defence and Veterans' Affairs, the cancer registry in each state (New South Wales, Victoria, Queensland, South Australia, Western Australia, Tasmania, Australian Capital Territory, Northern Territory) and the National Cancer Statistics Clearing House. Ethical approval was obtained for an additional Heart Health Survey to be sent to ARAD participants. All participants provide written informed consent.

Consent for publication

Not applicable.

\section{Competing interests}

The authors declare that they have no competing interests.

\section{Publisher's Note}

Springer Nature remains neutral with regard to jurisdictional claims in published maps and institutional affiliations.

\section{Author details}

${ }^{1}$ Institute of Bone and Joint Research, Kolling Institute, Northern Sydney Local Health District, Sydney, NSW, Australia. 'Department of Rheumatology, Royal North Shore Hospital, Reserve Road, St Leonards, NSW 2065, Australia. ${ }^{3}$ Sydney Medical School, University of Sydney, Sydney, NSW, Australia. ${ }^{4}$ Monash Department of Clinical Epidemiology, Cabrini Institute, Malvern, VIC, Australia. ${ }^{5}$ Department of Epidemiology and Preventive Medicine, School of Public Health and Preventive Medicine, Monash University, Clayton, VIC, Australia. ${ }^{6}$ Centre of Cardiovascular Research \& Education in Therapeutics, School of Public Health and Preventive Medicine, Monash University, Clayton, VIC, Australia. ${ }^{7}$ School of Public Health and Community Medicine, University of New South Wales, Sydney, NSW, Australia. ${ }^{8}$ Department of Rheumatology, St George Hospital, Kogarah, NSW, Australia.

Received: 6 March 2018 Accepted: 3 August 2018

Published online: 06 September 2018

\section{References}

1. Ogdie A, Yu Y, Haynes K, Love TJ, Maliha S, Jiang Y, et al. Risk of major cardiovascular events in patients with psoriatic arthritis, psoriasis and rheumatoid arthritis: a population-based cohort study. Ann Rheum Dis. 2015;74:326-32

2. Boehncke $\mathrm{W}-\mathrm{H}$, Boehncke S. Cardiovascular mortality in psoriasis and psoriatic arthritis: epidemiology, pathomechanisms, therapeutic implications, and perspectives. Curr Rheumatol Rep. 2012;14:343-8.

3. Avina-Zubieta JA, Choi HK, Sadatsafavi M, Etminan M, Esdaile JM, Lacaille D. Risk of cardiovascular mortality in patients with rheumatoid arthritis: a metaanalysis of observational studies. Arthritis Rheum. 2008;59:1690-7.

4. Solomon DH, Kremer J, Curtis JR, Hochberg MC, Reed G, Tsao P, et al. Explaining the cardiovascular risk associated with rheumatoid arthritis: traditional risk factors versus markers of rheumatoid arthritis severity. Ann Rheum Dis. 2010;69:1920-5.

5. Lacaille D, Avina-Zubieta JA, Sayre EC, Abrahamowicz M. Improvement in 5year mortality in incident rheumatoid arthritis compared with the general population-closing the mortality gap. Ann Rheum Dis. 2017;76:1057-63.

6. Myasoedova E, Gabriel SE, Matteson EL, Davis JM, Therneau TM, Crowson CS. Decreased cardiovascular mortality in patients with incident rheumatoid arthritis (RA) in recent years: Dawn of a new era in cardiovascular disease in RA? J Rheumatol. 2017;44:732-9. 
7. Raychaudhuri SK, Chatterjee S, Nguyen C, Kaur M, Jialal I, Raychaudhuri SP Increased prevalence of the metabolic syndrome in patients with psoriatic arthritis. Metab Syndr Relat Disord. 2010;8:331-4.

8. Sharma A, Gopalakrishnan D, Kumar R, Vijayvergiya R, Dogra S. Metabolic syndrome in psoriatic arthritis patients: a cross-sectional study. Int J Rheum Dis. 2013;16:667-73.

9. Pehlevan S, Yetkin DO, Bahadir C, Goktay F, Pehlevan Y, Kayatas K, et al. Increased prevalence of metabolic syndrome in patients with psoriatic arthritis. Metab Syndr Relat Disord. 2014;12:43-8.

10. Han C, Robinson DW, Hackett MV, Paramore LC, Fraeman KH, Bala MV. Cardiovascular disease and risk factors in patients with rheumatoid arthritis, psoriatic arthritis, and ankylosing spondylitis. J Rheumatol. 2006;33:2167-72.

11. Sinnathurai $P$, Lassere $M$, Buchbinder $R$, March $L$. Baseline characteristics of patients with psoriatic arthritis (PSA) from the Australian Rheumatology Association Database (ARAD) [abstract]. Intern Med J. 2015;45 Suppl 2:43.

12. Labitigan M, Bahce-Altuntas A, Kremer JM, Reed G, Greenberg JD, Jordan N, et al. Higher rates and clustering of abnormal lipids, obesity, and diabetes mellitus in psoriatic arthritis compared with rheumatoid arthritis. Arthritis Care Res (Hoboken). 2014;66:600-7.

13. Arumugam RAMA, McHugh NJ. Mortality and causes of death in psoriatic arthritis. J Rheumatol. 2012;89:32-5.

14. Jamnitski A, Symmons D, Peters MJ, Sattar N, Mclnnes I, Nurmohamed MT. Cardiovascular comorbidities in patients with psoriatic arthritis: a systematic review. Ann Rheum Dis. 2013;72:211-6.

15. Horreau C, Pouplard C, Brenaut E, Barnetche T, Misery L, Cribier B, et al. Cardiovascular morbidity and mortality in psoriasis and psoriatic arthritis: a systematic literature review. J Eur Acad Dermatol Venereol. 2013;27(Suppl 3):12-29.

16. Wong K, Gladman DD, Husted J, Long JA, Farewell VT. Mortality studies in psoriatic arthritis: results from a single outpatient clinic. I. Causes and risk of death. Arthritis Rheumatol. 1997:40:1868-72.

17. Mok CC, Kwok CL, Ho LY, Chan PT, Yip SF. Life expectancy, standardized mortality ratios, and causes of death in six rheumatic diseases in Hong Kong. China Arthritis Rheum. 2011;63:1182-9.

18. Ali Y, Tom BDM, Schentag $C T$, Farewell VT, Gladman DD. Improved survival in psoriatic arthritis with calendar time. Arthritis Rheum. 2007;56:2708-14.

19. Ogdie A, Haynes K, Troxel AB, Love TJ, Hennessy S, Choi H, et al. Risk of mortality in patients with psoriatic arthritis, rheumatoid arthritis and psoriasis: a longitudinal cohort study. Ann Rheum Dis. 2014;73:149-53.

20. Buckley C, Cavill C, Taylor G, Kay H, Waldron N, Korendowych E, et al. Mortality in psoriatic arthritis - a single-center study from the UK. J Rheumatol. 2010:37:2141-4.

21. Peters MJL, Symmons DPM, McCarey D, Dijkmans BAC, Nicola P, Kvien TK, et al. EULAR evidence-based recommendations for cardiovascular risk management in patients with rheumatoid arthritis and other forms of inflammatory arthritis. Ann Rheum Dis. 2010;69:325-31.

22. Agca R, Heslinga SC, Rollefstad S, Heslinga M, Mclnnes IB, Peters MJL, et al. EULAR recommendations for cardiovascular disease risk management in patients with rheumatoid arthritis and other forms of inflammatory joint disorders: 2015/2016 update. Ann Rheum Dis. 2016;76:17

23. Coates LC, Kavanaugh A, Mease PJ, Soriano ER, Laura Acosta-Felquer M, Armstrong AW, et al. Group for Research and Assessment of psoriasis and psoriatic arthritis 2015 treatment recommendations for psoriatic arthritis. Arthritis Rheumatol. 2016;68:1060-71.

24. Loza E, Lajas C, Andreu JL, Balsa A, González-Álvaro I, Illera O, et al. Consensus statement on a framework for the management of comorbidity and extraarticular manifestations in rheumatoid arthritis. Rheumatol Int. 2015;35:445-58.

25. Torre-Alonso JC, Carmona L, Moreno M, Galíndez E, Babío J, Zarco P, et al. Identification and management of comorbidity in psoriatic arthritis: evidence- and expert-based recommendations from a multidisciplinary panel from Spain. Rheumatol Int. 2017;37:1239-48.

26. Castaneda S, Loza E, Dauden E, Carmona L. Consensus statement on the Management of Comorbidity in patients with rheumatoid arthritis and psoriasis. J Rheumatol. 2016;43:990-1.

27. National Vascular Disease Prevention Alliance. Guidelines for the management of absolute cardiovascular disease risk. 2012. https:// heartfoundation.org.au/images/uploads/publications/Absolute-CVD-Risk-FullGuidelines.pdf. Accessed 18th Oct 2016.

28. Buchbinder R, March L, Lassere M, Briggs AM, Portek I, Reid C, et al. Effect of treatment with biological agents for arthritis in Australia: the Australian rheumatology association database. Intern Med J. 2007;37:591-600.

29. World Health Organisation. Obesity: preventing and managing the global epidemic. Report of a WHO Consultation. In: WHO Technical Report Series.
2000. http://www.who.int/nutrition/publications/obesity/WHO_TRS_894/en/. Accessed 18th Oct 2016

30. Work group recommendations: 2002 Exercise and Physical Activity Conference, St. Louis, Missouri. Session V: evidence of benefit of exercise and physical activity in arthritis. Arthritis Rheum. 2003;49:453-4.

31. World Health Organisation. Global Recommendations on Physical Activity for Health. 2010. http://www.who.int/dietphysicalactivity/publications/ 9789241599979/en/. Accessed 18th Oct 2016.

32. Zhang Z. Model building strategy for logistic regression: purposeful selection. Ann Transl Med. 2016;4:111.

33. Gulati AM, Semb AG, Rollefstad S, Romundstad PR, Kavanaugh A, Gulati S, et al. On the HUNT for cardiovascular risk factors and disease in patients with psoriatic arthritis: population-based data from the Nord-Trøndelag health study. Ann Rheum Dis. 2015;75:819-24.

34. Jafri K, Bartels CM, Shin D, Gelfand JM, Ogdie A. Incidence and management of cardiovascular risk factors in psoriatic arthritis and rheumatoid arthritis: A population-based study. Arthritis Care Res (Hoboken). 2017;69:51-7.

35. Kohl HW 3rd, Craig CL, Lambert EV, Inoue S, Alkandari JR, Leetongin G, et al. The pandemic of physical inactivity: global action for public health. Lancet. 2012:380:294-305

36. Langham S, Langham J, Goertz HP, Ratcliffe M. Large-scale, prospective, observational studies in patients with psoriasis and psoriatic arthritis: a systematic and critical review. BMC Med Res Methodol. 2011;11:32.

37. Centers for Disease Control and Prevention (CDC). Arthritis as a potential barrier to physical activity among adults with heart disease - United States, 2005 and 2007. MMWR Morb Mortal Wkly Rep. 2009:58:165-9.

38. Centers for Disease Control and Prevention (CDC). Arthritis as a potential barrier to physical activity among adults with diabetes - United States, 2005 and 2007. MMWR Morb Mortal Wkly Rep. 2008;57:486-9.

39. Hurkmans E, van der Giesen FJ, Vliet Vlieland TPM, Schoones J, Van den Ende ECHM. Dynamic exercise programs (aerobic capacity and/ or muscle strength training) in patients with rheumatoid arthritis. Cochrane Database Syst Rev. 2009:CD006853. https://doi.org/10. 1002/14651858.CD006853.pub2.

40. Abell J, Hootman J, Zack M, Moriarty D, Helmick C. Physical activity and health related quality of life among people with arthritis. J Epidemiol Community Health. 2005;59:380-5.

41. Sokka T, Häkkinen A, Kautiainen H, Maillefert JF, Toloza S, Mørk Hansen T, et al. Physical inactivity in patients with rheumatoid arthritis: Data from twenty-one countries in a cross-sectional, international study. Arthritis Care Res (Hoboken). 2008;59:42-50.

42. Shih M, Hootman JM, Kruger J, Helmick CG. Physical activity in men and women with arthritis: National Health Interview Survey, 2002. Am J Prev Med. 2006:30:385-93.

43. Hootman JM, Macera CA, Ham SA, Helmick CG, Sniezek JE. Physical activity levels among the general US adult population and in adults with and without arthritis. Arthritis Care Res (Hoboken). 2003;49:129-35.

44. van den Oever IAM, Heslinga M, Griep EN, Griep-Wentink HRM, Schotsman R, Cambach W, et al. Cardiovascular risk management in rheumatoid arthritis patients still suboptimal: the Implementation of Cardiovascular Risk Management in Rheumatoid Arthritis project. Rheumatology (Oxford). 2017;56:1472-8.

45. Der Ananian C, Wilcox S, Watkins K, Saunders R, Evans AE. Factors associated with exercise participation in adults with arthritis. J Aging Phys Act. 2008;16:125-43.

46. Wilcox S, Der Ananian C, Abbott J, Vrazel J, Ramsey C, Sharpe PA, et al. Perceived exercise barriers, enablers, and benefits among exercising and nonexercising adults with arthritis: Results from a qualitative study. Arthritis Care Res (Hoboken). 2006;55:616-27.

47. Baxter S, Smith C, Treharne G, Stebbings S, Hale L. What are the perceived barriers, facilitators and attitudes to exercise for women with rheumatoid arthritis? A qualitative study. Disabil Rehabil. 2016;38:773-80.

48. Khoja SS, Almeida GJ, Chester Wasko M, Terhorst L, Piva SR. Association of light-intensity physical activity with lower cardiovascular disease risk burden in rheumatoid arthritis. Arthritis Care Res (Hoboken). 2016:68:424-31.

49. Smolen JS, Breedveld FC, Burmester GR, Bykerk V, Dougados M, Emery P, et al. Treating rheumatoid arthritis to target: 2014 update of the recommendations of an international task force. Ann Rheum Dis. 2015;75:3.

50. Gossec L, Coates LC, de Wit M, Kavanaugh A, Ramiro S, Mease PJ, et al. Management of psoriatic arthritis in 2016: a comparison of EULAR and GRAPPA recommendations. Nat Rev Rheumatol. 2016:12:743-50. 